\title{
WAYANG KLITHIK ROBOT
}

\author{
Gandar Setiawan *)
}

\begin{abstract}
ABSTRACK
Wayang is a autentic culture from Indonesia. Wayang has many figure and character. It is main idea of this make the artwork. Inspiration of the artwork also from observation robot forms. Robot has the furious and futuristic form. Like the progression of technologi, form of robot also more experiencing form progression. Until now, form of robot still identic dan can not losed from imajinative forms.

This prossesing to make the artwork use created methode from Gustami, it is a three stages six steps creating craft artwork. First stage is eksploration consist of observation and finding refference steps. Second stage is desaigning consist of making the sketch and making the gambar teknik or modeling steps. Third stage is forming consist of create artwork and finished with value and evaluation steps.

Result of visual form is a three dimension artwork with futuristic robot form. Visual form the artwork is a transformastion of futuristic wayang klithik with robot form. The puppet figures are Wrekudara and Gatotkaca Combination form is a method for impression and aesthete value of the artwork.

Keywords: puppet, wayang klithik, robot, Wrekudara, Gatotkaca
\end{abstract}

\section{ABSTRAK}

Wayang merupakan budaya asli dari Indonesia. Wayang memiliki berbagai macam tokoh dan karakter. Wayang menjadi ide utama penciptaan dalam penciptaan karya ini. Inspirasi karya juga muncul dari pengamatan bentuk-bentuk robot. Robot memiliki bentuk yang variatif dan futuristik. Sesuai dengan perkembangan teknologi, bentuk robot juga mengalami perkembangan yang lebih bermacam-macam. Sampai saat ini, bentuk robot masih identik dan tidak bisa lepas dari bentuk-bentuk imajinatif.

Proses pembuatan karya seni ini menggunakan metode penciptaan dari Gustami, yaitu metode tiga tahap enam langkah dalam menciptakan karya seni kriya. Tahap pertama yaitu eksplorasi yang meliputi langkah pengamatan dan pencarian sumber pustaka. Tahap kedua merupakan tahap perancangan yang terdiri dari langkah pembuatan beberapa sketsa dan pembuatan gambar teknik ataupun model. Tahap yang ketiga yaitu tahap perwujudan yang terdiri langkah pengerjaan karya, dan diakhiri dengan penilaian juga evaluasi karya yang telah jadi.

Bentuk visual yang dihasilkan yaitu karya seni tiga dimensi dengan bentuk futuristik menyerupai robot. Bentuk visual karya merupakan penggabungan antara bentuk wayang

\footnotetext{
* Gandar Setiawan (robotgandar@gmail.com) Mahasiswa Program Penciptaan dan Pengkajian Pascasarjana ISI Yogyakarta
} 
klithik dengan bentuk robot. Tokoh wayang yang dibuat yaitu Wrekudara dan Gatotkaca. Perpaduan bentuk dilakukan sebagai cara untuk memberikan kesan dan nilai estetik pada karya.

Kata kunci: wayang, wayang klithik, robot, Wrekudara, Gatotkaca

\section{PENDAHULUAN}

Wayang merupakan salah satu budaya asli Indonesia yang identik dengan penggabungan berbagai macam seni didalamnya. Wayang sebagai salah satu budaya yang adiluhung meliputi penggabungan antara "seni kriya, seni sastra, seni tutur, seni peran, dan seni perlambangan" (Ensiklopedi Wayang Indonesia jilid V, 1999: 247). Sebagai budaya yang adiluhung, wayang harus selalu dilestarikan agar tetap terjaga eksistensinya. Penciptaan karya ini terinspirasi pada bentuk visual wayang yang memiliki karakter futuristik yang digabungkan dengan bentuk robot, dengan material kayu. Hal ini dilakukan untuk memberikan gaya baru yang akan ditampilkan dalam karya seni. Dalam penciptaan karya ini, tujuan yang ingin dicapai yaitu menciptakan karya dengan ide dasar robot dengan dengan menggabungkan bentuk wayang, sehingga karya yang dihasilkan berupa wayang klitik. Dengan menggabungkan bentuk wayang dan robot, maka terciptalah nuansa baru antara budaya modern dengan budaya tradisional yang dapat memberikan manfaat edukasi, budaya dan seni.

Robot dikenal sebagai alat yang memiliki fungsi membantu pekerjaan manusia. Banyak negara maju menciptakan robot untuk melakukan hal-hal yang sulit atau beresiko jika dilakukan oleh manusia.
Awal munculnya istilah robot berasal dari para ilmuwan biologi dan penulis novel bernama Wright Karel Capek pada tahun 1921 di negara Ceko. Pada waktu itu robot dijadikan simbol perbudakan yang ditampilkan dalam drama pertunjukkan dengan judul Rossum's Universal Robots. Wright Karel Capek menuliskan istilah robot dalam karya tulisannya, dan sejak itu pula kata robot mulai familiar dan dikenal banyak orang. Dalam bahasa Ceko, "robot berasal dari kata robota" (Izwar Lubis, 2013: 1).

Penciptaan ini mengacu pada beberapa teori yang mendukung terwujudnya karya. Teori-teori pendukung dalam proses penciptaan karya ini berkaitan dengan metodologi penciptaan, teori estetika, dan teori tanda. Setiap teori memiliki karakter dan fungsi sendiri-sendiri tetapi masih memiliki keterkaitan antara satu dengan lainnya.

Teori estetika merupakan teori yang berhubungan dengan keindahan sebuah objek. Estetika adalah "segala hal yang berkaitan dengan keindahan" (The Liang Gie, 1997: 15). Pada penciptaan ini objek yang dimaksudkan adalah karya seni, berkaitan dengan elemen-elemen seni rupa yang akan ditampilkan. Teori lainnya yang dipakai yaitu teori dari Dharsono Sony Kartika, tentang elemen-elemen seni rupa yang terdiri dari "komposisi garis, bidang, warna, yang dipadukan secara menyatu, 
selaras, harmoni" (Dharsono Soni Kartika, 2004:12).

Teori tanda atau semiotik yang digunakan dalam penciptaan ini adalah teori dari C.S. Peirce. Peirce menjelaskan tentang hubungan-hubungan tanda yang sering dikenal dengan trikotomi Peirce. Teori ini memuat hubungan tanda dengan tanda, tanda dengan objek, dan tanda dengan penafsir tanda (Arthur Asa berger, 2010: 33). Trikotomi Peirce berisikan tentang hubungan tiga unsur yang saling melengkapi yaitu "objek, representamen, dan interpretan" (Kris Budiman, 2011: 17). Teori ini berfungsi untuk menunjukkan karakter dari tokoh wayang yang diciptakan.

Metode penciptaan yang digunakan adalah metode penciptaan dari Gustami. "Teori penciptaan Gustami terdiri dari tiga tahap - enam langkah penciptaan seni kriya. Pertama tahap eksplorasi yang meliputi pengamatan, dan pencarian sumber penciptaan. Kedua, tahap perancangan yaitu membuat beberapa sketsa, dan pembuatan gambar teknik. Tahap ketiga, perwujudan yaitu proses pembentukan, dan dilanjutkan penilaian dan evaluasi karya yang telah jadi" (Gustami, 2004: 29-32).

\section{PEMBAHASAN}

\section{Tahap Eksplorasi}

Tahap ini merupakan tahap awal dalam menciptakan karya seni. Pada langkah ini, dilakukan dua tahapan yang terdiri dari pengamatan objek yang dijadikan sumber ide yaitu wayang dan robot, serta pencarian berbagai macam referensi yang berkaitan dengan ide penciptaan. Penciptaan karya ini bersumber dari tokoh wayang dan film tentang robot dengan karakter futuristiknya. Tokoh wayang yang diambil yaitu Wrekudara dan Gatotkaca. Pemilihan tokoh wayang Wrekudara karena diangap sebagai salah satu tokoh yang tangguh dan kuat,yang memiliki karakter menggunakan dodot poleng bang bintulu dan memiliki senjata kuku pancanaka sebagai anugrah dari keturunan Batara Bayu (Ensiklopedi Wayang Indonesia jilid II, 1999: 291). Gatotokaca dipilih karena memiliki kekuatan yang tidak kalah dengan Wrekudara. Sebagai anak dari Wrekudara, Gatotkaca menjadi tokoh pahlawan dari keluarga Pandawa.

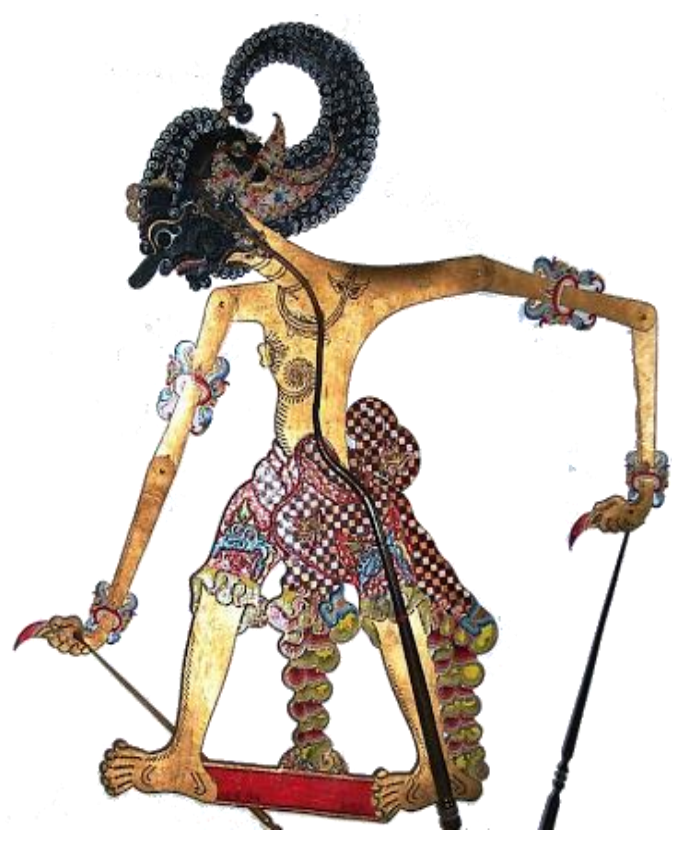

Gambar 1. Tokoh Bima dalam pewayangan gagrak Yogyakarta (Sumber: http://crowsinside. blogspot.com/p/laman-unduh.html), Diunduh: tanggal 29 November 2014, jam 19.00 WIB Oleh: Gandar Setiawan 


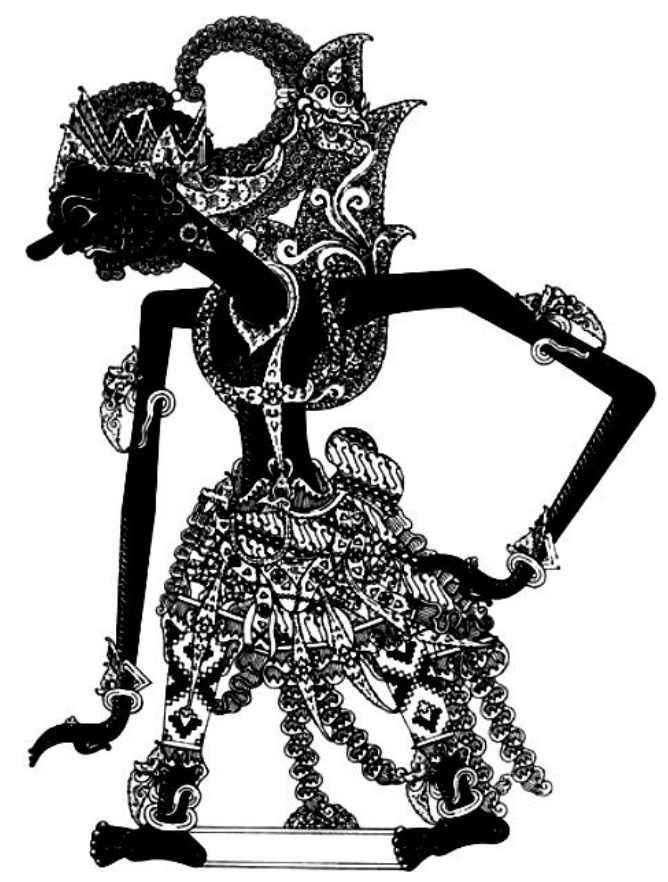

Gambar 2. Tokoh Gatotkaca dalam pewayangan gagrak Surakarta (Ensiklopedia Wayang Indonesia)

Selain terinspirasi oleh tokohtokoh wayang, karya yang dibuat juga teriinspirasi oleh film tentang robot. Beberapa film tersebut adalah I Robot, Transformers, Real Steel, Astroboy, Pacific Rim, dan masih banyak lagi film-film lainnya. Film-film tersebut menampilkan kecanggihan teknologi yang disimbolkan dalam bentuk robot. Seperti yang ditampilkan dalam beberapa film diatas bahwa robot dijadikan alat untuk melakukan pekerjaan yang sulit dilakukan manusia. Dalam film I Robot memperlihatkan adegan bagaimana sebuah robot humanoid yang mencoba memberikan pertolongan kepada manusia dengan dengan susah payah, penuh resiko, dan dramatis. Hal ini menyimbolkan bahwa teknologi robot dimanfaatkan manusia sebagai alat memenuhi kebutuhan manusia yang sulit dilakukan oleh manusia. Hal ini berkaitan dengan awal munculnya istilah robot, yang menyatakan tiga hukum robot yaitu pertama robot tidak diperbolehkan melukai manusia, atau berdiam diri membiarkan manusia celaka, kedua sebuah robot harus mematuhi perintah yang diberikan oleh manusia kecuali perintah tersebut bertentangan dengan hukum yang pertama, dan ketiga robot harus dapat melindungi dirinya sendiri selama itu tidak bertentangan dengan hukum yang pertama dan hukum kedua.

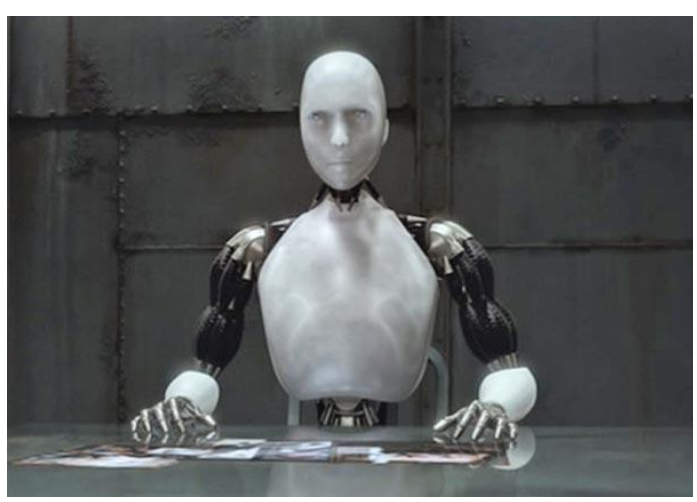

Gambar 3. Bentuk robot dalam film I, Robot.

(Sumber: http://static.comicvine.com/ uploads/original/7/74798/1429066-so.jpg) Diunduh: tanggal 23 Oktober 2014, jam 20.00 WIB Oleh: Gandar Setiawan

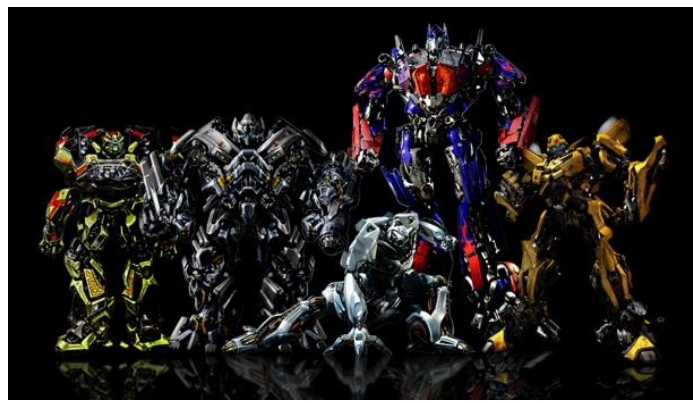

Gambar 4. Bentuk robot dalam film Transformers. (Sumber:'http://lostbrosclubhouse.com/wpcontent/ uploads/2014/07/transformers_autobots_by_megav alve.jpg) Diunduh: tanggal 23 Oktober 2014, jam 20.00 WIB, Oleh: Gandar Setiawan 


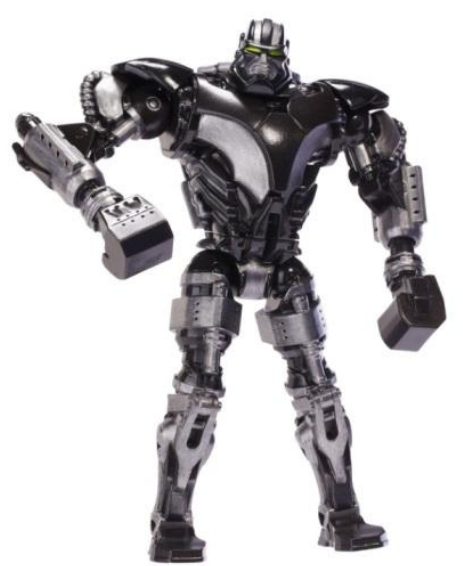

Gambar 5. Bentuk robot dalam film Real Steel. (Sumber: http://ecx.images-amazon.com/images/ I/81AUEQixLmL._SL1500_.jpg), Diunduh: tanggal 23 Oktober 2014, jam 20.00 WIB, Oleh: Gandar Setiawan

Selain terinspirasi dari film-film bertema robot, penciptaan ini juga terinspirasi dari bentuk-bentuk robot yang sudah ada. Namun demikian, dalam proses ini tidak semena-mena membuat bentuk karya yang sudah ada. Ada pengembangan dan hal baru yang ditampilkan yang dapat ditinjau dari segi konsep, bahan, bentuk, dan fungsinya. Berikut adalah gambargambar robot dan beberapa karya seni yang berbentuk robot.

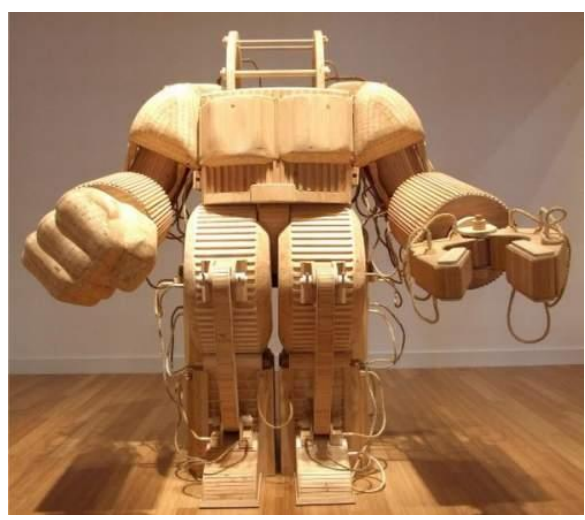

Gambar 6. Karya patung berbentuk robot (Sumber: http://www.smosh.com/smoshpit/photos/25-amazing-wood-sculptures) Diunduh: tanggal 23 Oktober 2014, jam 20.00 WIB Oleh: Gandar Setiawan

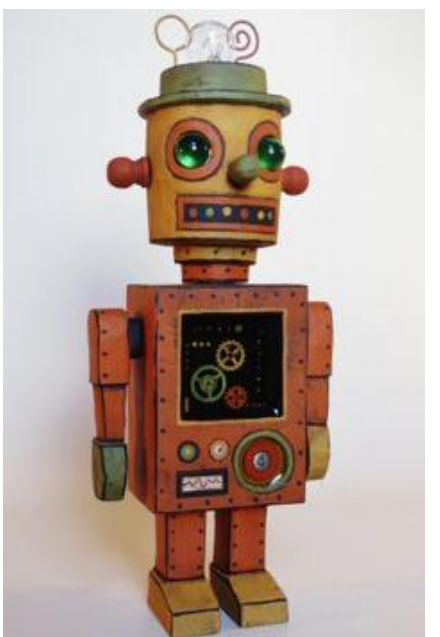

Gambar 7. Karya patung berbentuk robot (Sumberhttp://media-cacheak0.pinimg.com/236x/e4/c5/ba/e4c5ba436869041d 732f34dc3861bca8.jpg)

Diunduh: tanggal 23 Oktober 2014, jam 20.00 WIB Oleh: Gandar Setiawan
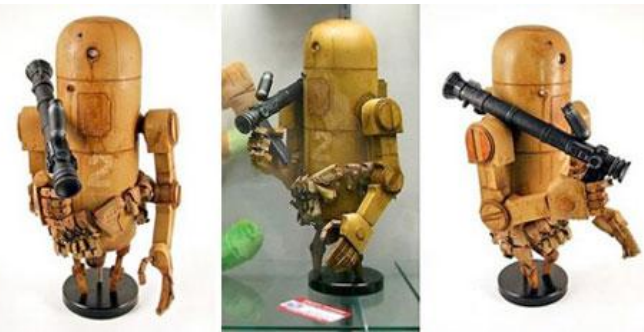

Gambar 8. Karya kerajinan berbentuk robot (Sumber: http://gadgets.boingboing.net/ 2007/08/31/ashley-woods-bertie.html) Diunduh: tanggal 23 Oktober 2014 Oleh: Gandar Setiawan

\section{Tahap Perancangan}

Tahap ini merupakan tahap pembuatan sketsa dan desain. Desain dibuat agar bentuk yang diinginkan lebih terpetakan. Dengan menggunakan sketsa dan desain sebagai acuan, akan mempermudah mewujudkannya. Hal ini juga memberikan peluang untuk memunculkan ide lain ditinjau dari segi bentuk yang akan diwujudkan. Langkah setelah membuat sketsa dan desain yang dilanjutkan pembuatan model potongan 
pola. Langkah ini dilakukan untuk memastikan ketepatan desain dan bentuk yang akan disesuaikan dengan konstruksi dan komposisi bentuk.

Dalam perancangan karya ini dihasilkan 3 desain alternative dan model po

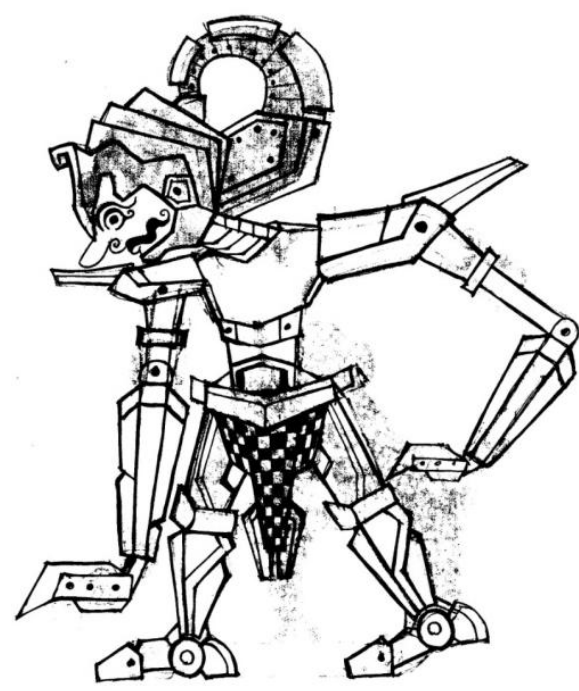

Gambar 9. Sketsa 1

(Sketsa: Gandar Setiawan, 2014)

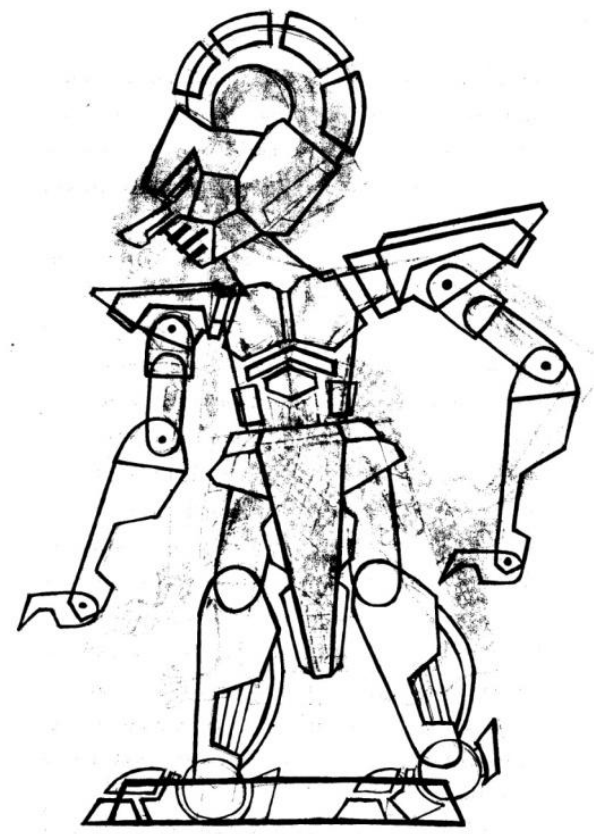

Gambar 10. Sketsa 3

(Sketsa: Gandar Setiawan, 2014)

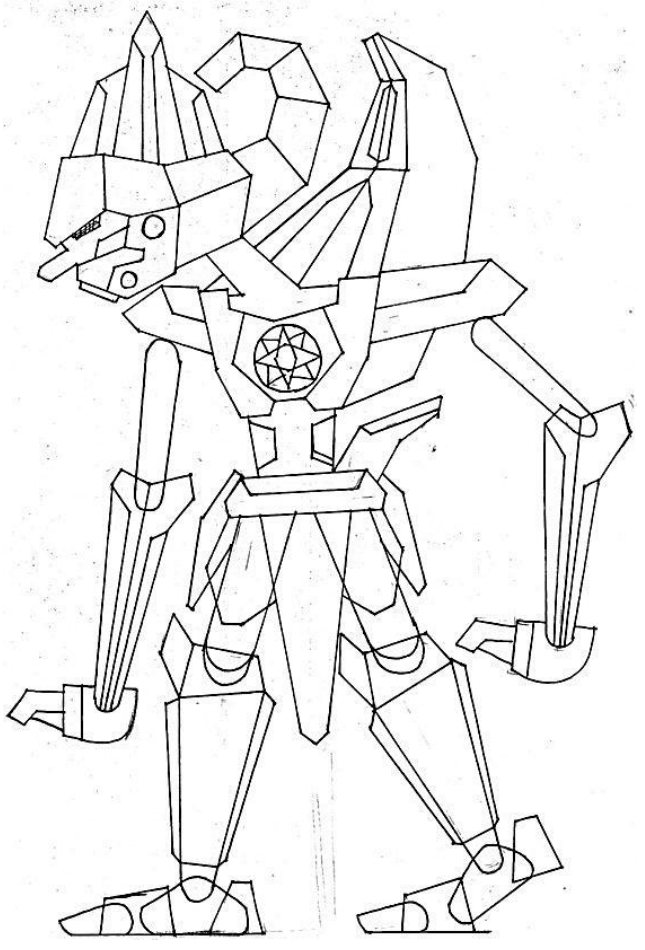

Gambar 11. Sketsa 4

(Sketsa: Gandar Setiawan, 2014)

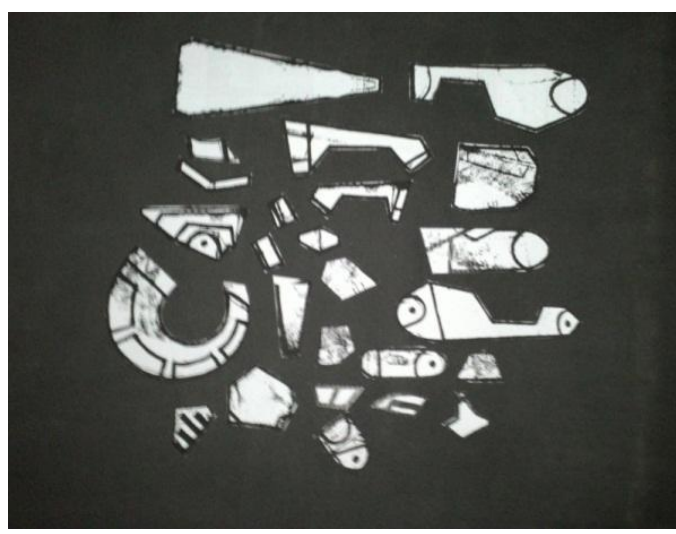

Gambar 12. Model potongan pola bagian robot (Foto: Gandar Setiawan, 2014)

\section{Tahap Perwujudan}

\section{Pemilihan Bahan}

Bahan yang digunakan adalah kayu mindi, atau dalam bahasa latin disebut Melia azedarach. Kayu ini merupakan kayu yang berasal dari daerah tropis. Di Yogyakarta kayu mindi masih minim peminatnya. Karakter kayu ini yaitu 
memiliki warna dominan coklat muda, dan serat besar dan memiliki serat yang cukup bagus . Kayu mindi termasuk dalam kategori dengan kekerasan sedang.

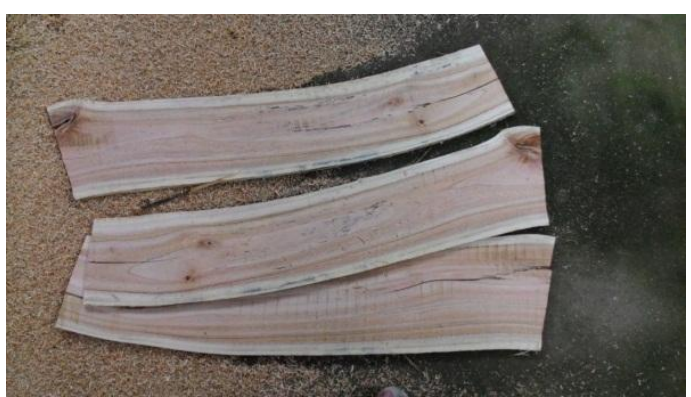

Gambar 13. Kayu mindi

(Foto: Gandar Setiawan, 2014)

Jenis kayu lainnya yang digunakan untuk pembuatan karya ini adalah kayu jati dan kayu kamper. Kayu jati (Tectona grandia) termasuk dalam jenis kayu keras, memiliki karakter kayu ulet, berwarna coklat dan memiliki tekstur serat yang meliuk-liuk. Kayu ini mayoritas hidup di wilayah pulau Jawa, dan kualitas yang bagus berada didaerah Jawa Tengah dan Jawa Timur. Sedangkan kayu kamper merupakan kayu yang berasal dari daerah Kalimantan, kayu ini memiliki warna merah kecoklatan. Termasuk dalam tingkatan kayu keras.

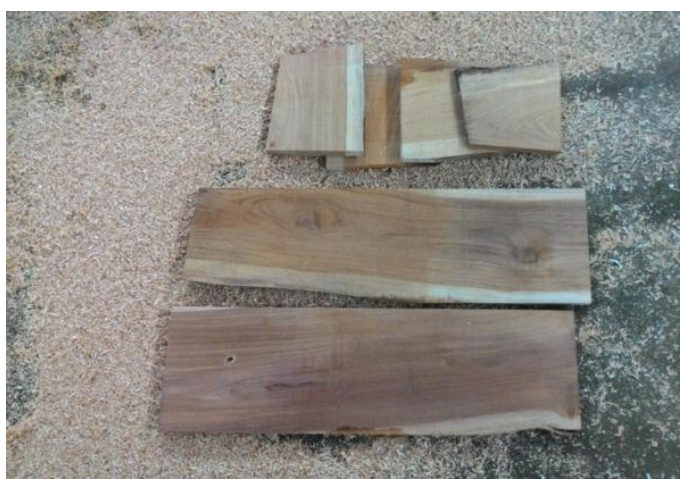

Gambar 14. Kayu Jati

(Foto: Gandar Setiawan, 2014)

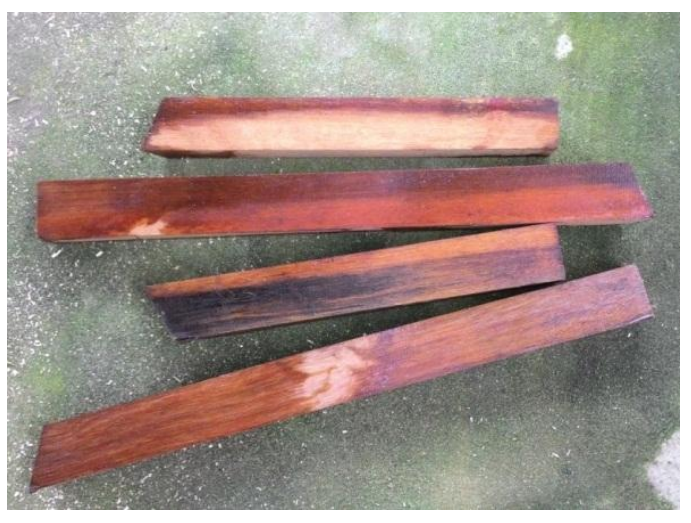

Gambar 15. Kayu Kamper

(Foto: Gandar Setiawan, 2014)

\section{Teknik yang dipakai}

Teknik utama yang digunakan dalam pembuatan karya ini adalah teknik potong (cutting). Teknik potong menjadi teknik yang paling banyak digunakan dalam proses penciptaan karya ini.penerapan teknik ini dilakukan menggunakan peralatan pendukung. Alat tersebut yaitu mesin gergaji skrol (scroll saw) dan gergaji bundar (circle saw),

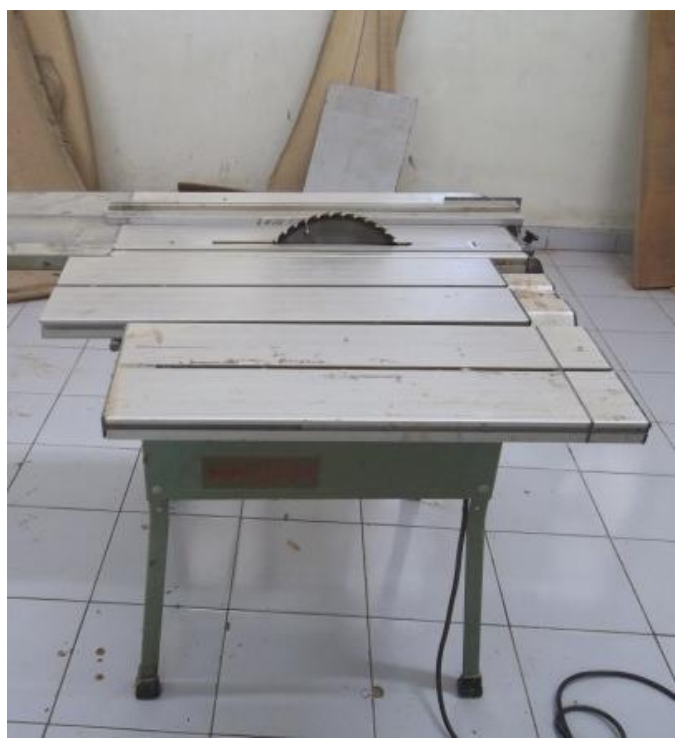

Gambar 16. Circle saw

(Foto: Gandar Setiawan, 2013) 


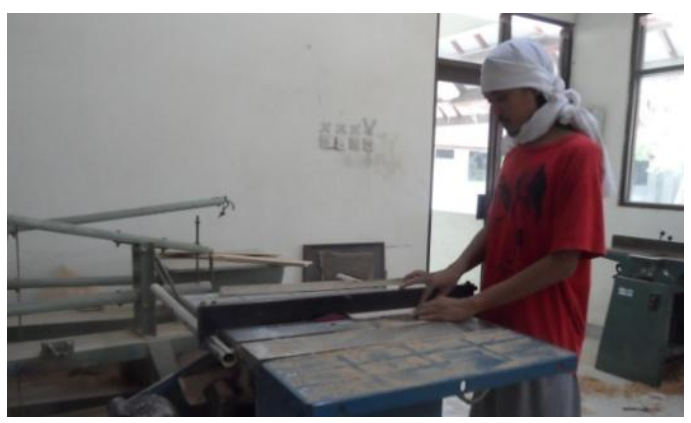

Gambar 17. Proses pemotongan kayu menggunakan Circle saw (Foto: Ecky Kartawitanto, 2013)

Gergaji ini digunakan untuk memotong dan membelah kayu. Ukuran diameter mata gergaji adalah 10 inchi dengan kapasitas kekuatan dinamo yang mampu berputar $20000 \mathrm{rpm}$.

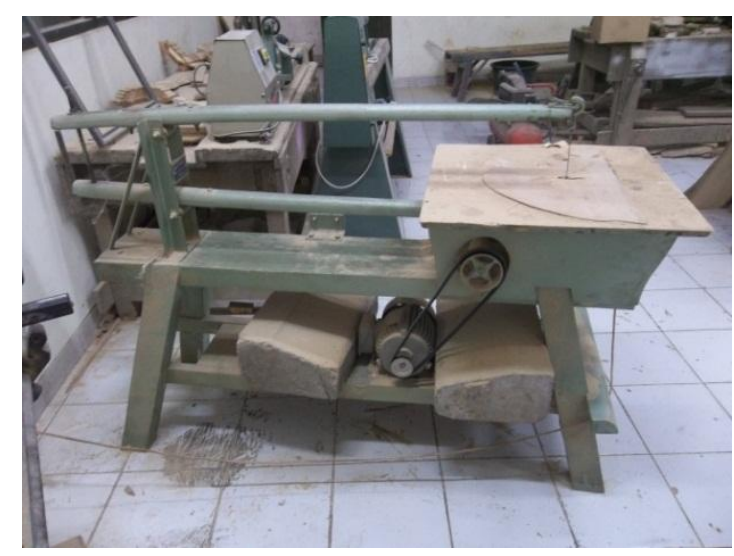

Gambar 18. Scroll saw

(Foto: Gandar Setiawan, 2013)

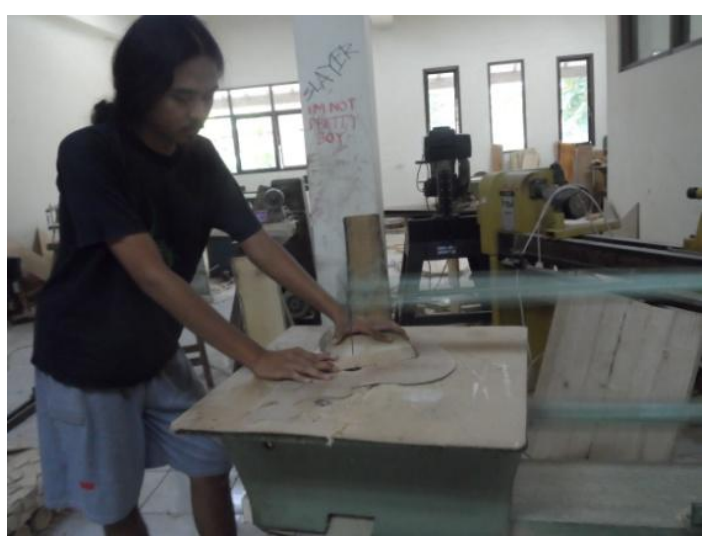

Gambar 19. Proses pemotongan kayu menggunakan Scroll saw (Foto: Ecky Kartawitanto, 2013)
Gergaji skrol ini merupakan modifikasi dari mesin skrol kecil. Alat ini menggunakan dinamo berkekuatan 1,5 tenaga kuda. Mampu berputar 5000 rpm.

Dari hasil proses pemotongan kayu dengan menggunakan circle saw dan scroll saw, akan dihasilkan potongan-potongan yang siap untuk dirangkai. Setelah proses perangkaian selesai, dilanjutkan proses finishing yang meliputi penghalusan menggunakan amplas dan proses penutupan pori-pori kayu menggunakan sanding sealler. Proses selanjutnya yaitu pengamplasan ulang dan dilanjutkan pengecatan pada beberapa bagian saja sesuai konsep. proses terakhir yaitu coating menggunakan clear gloss. 


\section{Wujud Karya}

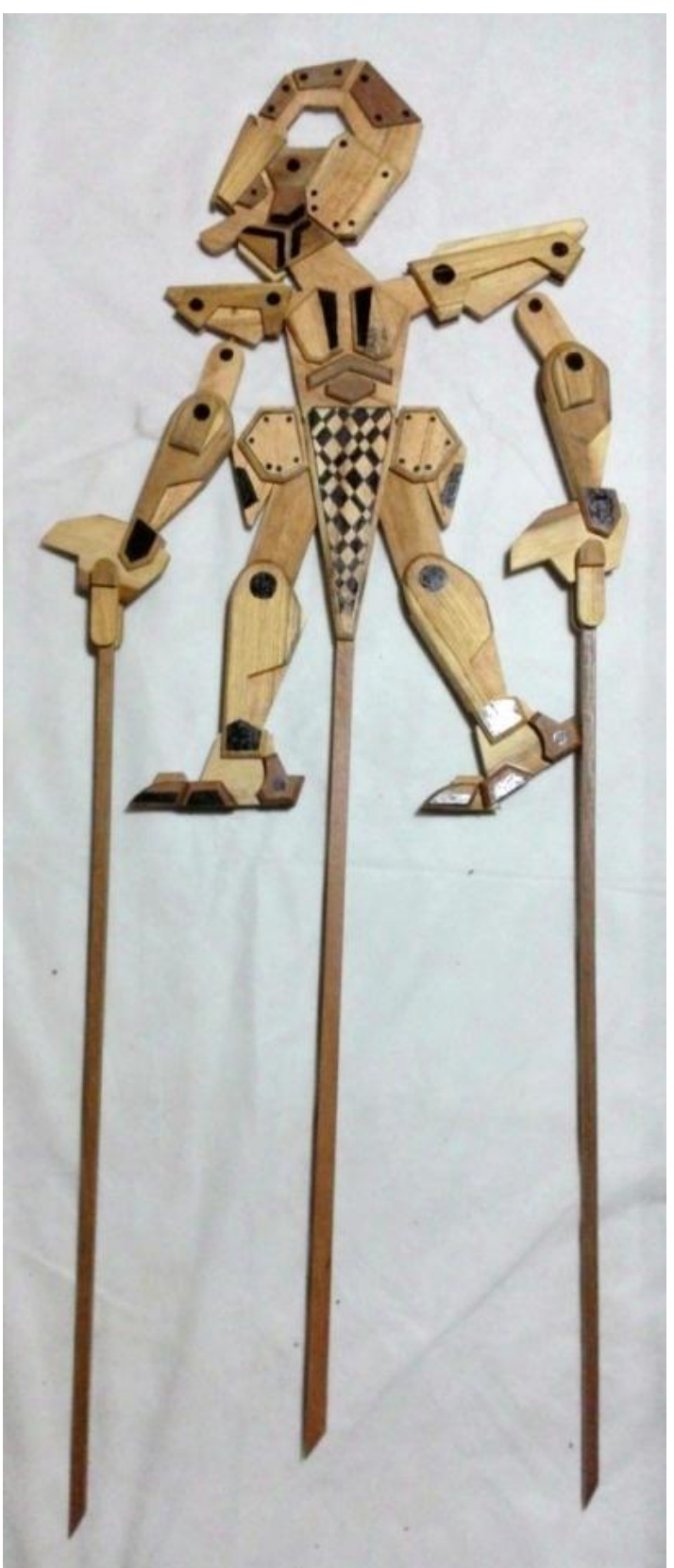

Gambar 20. Karya 1 "Wrekudara".

(Foto: Gandar Setiawan, 2015)

Karya ini berjudul "Wrekudara".

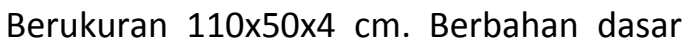
kayu jati, mindi, dan kayu kamper. Karya ini ingin menggambarkan sosok Wrekudara yang kuat dan perkasa. Untuk

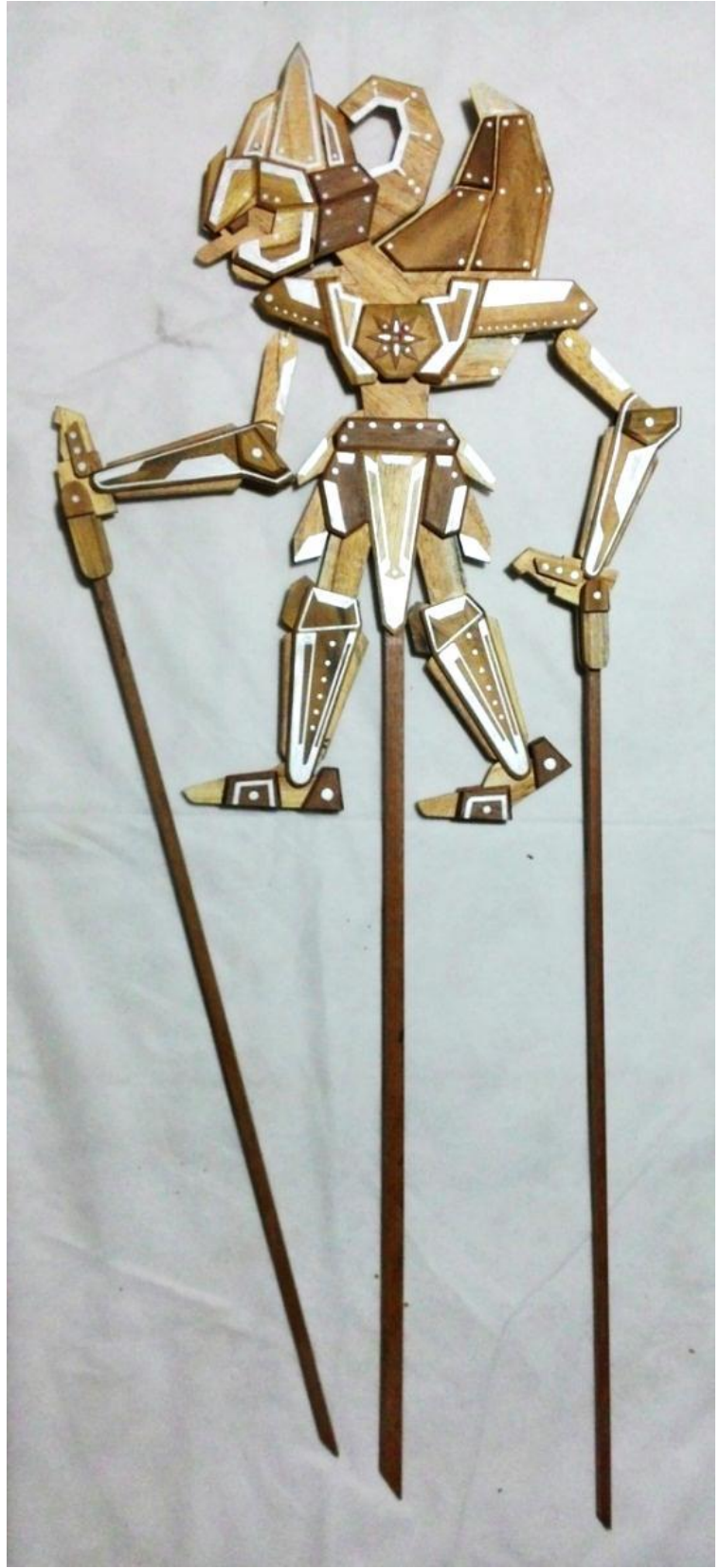

Gambar 21. Karya 2 "Gatotkaca”.

(Foto: Gandar Setiawan, 2015)

memperlihatkan tokoh Wrekudara karya dibuat berdasarkan karakter luarnya, yaitu memiliki senjata Kuku Pancanaka sebagai senjata yang khas dari Wrekudara, serta menggunakan dodot poleng bang bintulu. 
Karya ini berjudul "Gatotkaca".

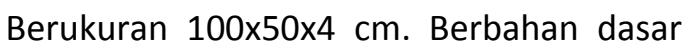
kayu jati, mindi, dan kayu kamper. Untuk memperlihatkan tokoh Gatotkaca karya dibuat berdasarkan karakter luarnya, yaitu memiliki kekuatan seperti besi yang diwakili oleh warna logamarna logam, karena Gatotkaca terkenal dengan julukan otot kawat balung wesi. Sedangkan karakter lain yang ingin ditunjukkan yaitu simbol bintang pada dada sebagai simbol dari kutang Antakusuma yang dapat digunakan untuk terbang dan melindungi diri.

\section{PENUTUP}

Melalui proses yang telah dilakukan karya ini dapat terwujud, Bentuk yang dihasilkan yaitu bentuk wayang yang dipadukan dengan bentuk robot, yaitu tokoh Wrekudara dan Gatotkaca. Karya ini menampilkan wayang klithik dengan karakter robot yang dapat dimainkan seperti layaknya wayang klithik pada umumnya. Dengan diciptakannya karya ini maka terjadi perpaduan unsur budaya tradisi dan modern, sehingga nilai-nilai tradisi yang tada pada karya muncul sebagai karakter khas Indonesia yaitu wayang.

\section{KEPUSTAKAAN}

Budiman, Kris (2011), Semiotika Visual: Konsep, Isu,dan Problem Ikonisitas, Penerbit Jalasutra, Yogyakarta.

Gustami, SP. (2004), Proses Penciptaan Seni Kriya: Untaian Metodologis, Program Pascasarjana S2
Penciptaan Dan Pengkajian Seni ISI

Yogyakarta, Yogyakarta.

Liang Gie, The (1997), Filsafat Keindahan, Yogyakarta: Adipura.

Lubis, Izwar (2013), "Bahan Ajar Pendidikan Teknik Mesin dan Robotika", Sumber dari UPT Universitas Negeri Medan Sumatra Utara, Medan.

Sony Kartika, Dharsono (2004), Seni Rupa Modern, Bandung: Rekayasa Sains

Tim Penulis Sena Wangi (1999), "Ensiklopedi Wayang Indonesia", jilid II, Sena Wangi, Jakarta.

\section{Webtografi}

http://crowsinside.blogspot.com/p/lamanunduh.html, 29 November 2014, jam 19.00 WIB

http://ecx.images-

amazon.com/images/I/81AUEQixLmL._SL1 500_.jpg, 23 Oktober 2014, jam 20.00 WIB

http://gadgets.boingboing.net/2007/08/31 /ashley-woods-bertie.html, 23 Oktober 2014, jam 20.00 WIB

http://lostbrosclubhouse.com/wp-content /uploads/2014/07/ transformers autobots by_megavalve.jpg, 23 Oktober 2014, jam 20.00 WIB

http://media-cacheak0.pinimg.com/236x/e4/c5/ba/e4c5ba43 
6869041d732f34dc386 1bca8.jpg, 23

Oktober 2014, jam 20.00 WIB

http://static.comicvine.com/uploads/origin al/7/74798/1429066-so.jpg, 23 Oktober 2014, jam 20.00 WIB

http://www.smosh.com/smoshpit/photos/25-amazing-wood-sculptures, 23 Oktober 2014, jam 20.00 WIB

http://1.bp.blogspot.com/_8hg7KdpvuOY/ TQnRilf7qil/AAAAAAAAAOA/UoWi763Wes/s1600/bima9.jpg, 29 November 2014, jam 20.00 WIB 